\title{
A correlation study of lipid profile with body mass index and waist hip ratio in Rohilkhand region
}

\author{
Mallick A. K. ${ }^{1}$, Ahsan M. ${ }^{2}$, Das B. ${ }^{3}$, Rai S. ${ }^{4}$ \\ ${ }^{1}$ Dr. Ayaz Khurram Mallick, Associate Professor, Department of Biochemistry, ${ }^{2}$ Dr. Marya Ahsan, Associate Professor, \\ Department of Pharmacology, ${ }^{3}$ Dr. Biswajit Das, Professor and Head, Department of Biochemistry, ${ }^{4}$ Dr. Saurav Rai, Post \\ Graduate Student, Department of Biochemistry, all authors are affiliated with Rohilkhand Medical College and Hospital, \\ Bareilly, UP, India.
}

Corresponding Author: Dr. Ayaz Khurram Mallick, Associate Professor, Department of Biochemistry, Rohilkhand Medical College and Hospital, Bareilly. Email: ayazmallick@yahoo.com

\begin{abstract}
Background: Central or abdominal obesity is associated with metabolic disorders such as hypertension, diabetes mellitus and cardio vascular disease (CVD). Anthropometric tools especially BMI is commonly used to categorize obesity. BMI, calculated from the weight and height of an individual, represents generalized fat distribution. Waist hip ratio (WHR) is more reliable anthropometric tool for measuring abdominal obesity as it takes waist circumference into consideration. Therefore, this study was undertaken to study the correlation of dyslipidemia with BMI and WHR and conclude if WHR could be used as a reliable tool for identifying high risk patients. Materials and Methods: Two hundred participants aged between 35 to 45 years were randomly chosen. Lipid profile of all the participants was determined. These participants were divided into three groups based on their BMI. Same participants were also divided based on their WHR into two groups - Low risk and high risk. Mean of lipid profile was analyzed for significance by ANOVA and independent $t$ test using SPSS 23.0. Correlation of dyslipidemia and BMI and WHR was analyzed using Pearson Coefficient. $\mathrm{P}<0.05$ was considered significant. Result: Participants with WHR in the high-risk category had TC/HDL ratio of $3.8 \pm 0.5$ which was similar to those with $\mathrm{BMI}>30 \mathrm{Kg} / \mathrm{m}^{2}$. Pearson correlation coefficient of Total cholesterol, LDL-C and TC/HDL with WHR was $0.505,0.484$ and 0.528 respectively which was stronger than that with BMI. Conclusion: WHR is a reliable tool to identify patients who are at high risk to develop CVD and other metabolic diseases.
\end{abstract}

Key words: BMI, Cardiovascular risk, Waist Hip ratio

\section{Introduction}

The World Health Organization defines obesity as an abnormal or excessive accumulation of fat which impairs health. The number of obese patients has increased considerably in the last decade making obesity a world-wide epidemic. In line with the global trend, almost 25 to $50 \%$ of the urban Indian population are overweight or have abdominal obesity [1]. Obesity is associated with hypertension, fasting and postprandial hyperglycemia, and dyslipidemia characterized by elevations in triglycerides, production of small, dense LDL particles and reduced HDL cholesterol [2,3]. Dyslipidemia of obesity is thus associated with an adverse cardiovascular risk resulting in high incidence of cardiovascular morbidity and mortality.

Manuscript received: $6^{\text {th }}$ March 2018

Reviewed: $16^{\text {th }}$ March 2018

Author Corrected: 24 $4^{\text {th }}$ March 2018

Accepted for Publication: $28^{\text {th }}$ March 2018
A very simple and most widely used measure of body size is the Body Mass Index (BMI), which relates weight to height. BMI is frequently used to estimate the prevalence of obesity within a population. A BMI $\geq 25$ $\mathrm{Kg} / \mathrm{m}^{2}$ is associated with morbidity where as a BMI $\geq$ $30 \mathrm{Kg} / \mathrm{m}^{2}$ is associated with morbidity and mortality [4]. Although the BMI is commonly used to assess the obesity, it does not reflect the distribution of body fat especially the abdominal region.

Excessive deposition of adipose tissue around the viscera, also called as the apple-shaped obesity, are thought to be associated with metabolic syndrome [5]. Adipose tissue from the visceral fat releases free fatty acids adipokines such as resistins, leptin, adinopectin and retinol-binding protein 4 which affects the insulin sensitivity. In addition, macrophages from the adipose 
tissue releases cytokines like TNF- $\alpha$ and IL-6 which are involved in pathogenesis of cardiovascular diseases $[6,7]$. Thus, other anthropometric indices such as waist circumference (WC), waist-to-height ratio (W/Ht), and waist-to-hip ratio (WHR) have been used as alternatives to BMI.

Waist circumference is increasingly being accepted as the best anthropometric indicator of abdominal adiposity and metabolic risk $[4,8]$. In view of this, this study was done with the aim to compare BMI and Waist Hip Ratio with dyslipidemia in Indian population.

\section{Material and Methods}

This study was carried out in the Department of Biochemistry, Rohilkhand Medical College Bareilly, from January 2015 to December 2015. Ethical committee clearance was taken prior to the study.

\section{Sample size:}

A total of 200 subjects were randomly selected for the study after taking their informed consent. Patients with Diabetes Mellitus, hypertension, cardiovascular disease, liver and kidney disorder and those on lipid lowering agents were excluded from the study. Height in meters and weight in kilograms were recorded and BMI was calculated. Based on the BMI, the subjects were divided as follows

Healthy weight (Group 1): Subjects with BMI 18.5 to 24.9

Overweight (Group 2): Subject with BMI 25.0 to 29.9

Obese (Group 3): Subject with BMI 30.0 and above.

In order to study the lipid profile in patients with abdominal obesity these subjects were also divided into two groups based on their waist hip ratio irrespective of their BMI. Waist and hip circumference was measured twice to the nearest $0.5 \mathrm{~cm}$, with a flexible but nonelastic measuring tape. Waist circumference was measured at the approximate midpoint between the lowest rib and the top of the iliac crest.

Hip circumference was measured at the maximum circumference of the buttocks posteriorly and the symphysis pubis anteriorly, in a horizontal plane [9]. Internationally accepted cut-off points for WHR are 0.90 for men and 0.85 for women based on the National Cholesterol Education Program were considered. Men with WHR of below 0.9 and females below 0.85 below were grouped as low risk, where as those men and women with waist circumference $\geq 0.9$ and $\geq 0.85 \&$ were grouped as high risk.

Biochemical analysis- Two $\mathrm{ml}$ venous blood sample was collected after a fasting period of $10-12$ hours. Sample was then centrifuged and serum was used for the analysis. Lipid profile was determined by Erba 360 auto analyzer by using enzymatic methods such as CHOD-PAP method total cholesterol (TC), GPO-PAP method for triglycerides (TG) and direct method for High Density Lipoprotein - Cholesterol (HDL-C) and Low Density Lipoprotein - Cholesterol (LDL-C). TC/ HDL ratio was calculated.

Statistical analysis- Statistical analysis was done using the statistical package for social sciences (SPSS) version 23.0. All data is expressed as mean \pm S.D. Significance of mean was analyzed using one way analysis of variance (ANOVA) for BMI groups and independent $t$ test for WHR groups. The mean of the three groups was compared using multiple comparison post hoc test. Pearson correlation coefficient was used to analyze the correlation of lipid parameters with BMI and WHR. P value of $<0.05$ was considered statistically significant.

\section{Results}

The mean age of the participants in this study was $39.23 \pm 3.43$ years. In was observed that 70 participant had BMI with in healthy range, 86 participants were overweight and 44 were having BMI of 30.0 and above and hence belonged to obese category (Table 1). As seen in Table 2, study of lipid profile showed that the total cholesterol, serum triglyceride level and TC/HDL ratio were significantly elevated in participant belong to overweight and obese group as compared to those in healthy group.

Although there was increase in serum LDL levels in overweight and obese participant, this increase was neither clinically nor statistically significant. Though the serum HDL levels were comparable between the participant in the normal and overweight categories, participants of the obese group has statistically significant lower levels of HDL in comparison to both the groups. Table 3 shows the correlation between parameters of lipid profile and BMI. A significant correlation was seen between increasing total cholesterol, triglyceride and TC/HDL ratio and decreasing HDL levels with increasing BMI. 
Original Research Article

Table-1: Table showing the distribution of the participants based on their body mass index and waist hip ratio

\begin{tabular}{|c|c|c|c|c|c|}
\hline & \multicolumn{3}{|c|}{ BMI } & \multicolumn{2}{c|}{ Waist Hip Ratio } \\
\hline & $\begin{array}{c}\text { Healthy } \\
(18.5 \text { to } \\
24.9)\end{array}$ & $\begin{array}{c}\text { Overweight } \\
(25.0 \text { to } \\
29.9)\end{array}$ & $\begin{array}{c}\text { Obese } \\
(30.0 \text { and } \\
\text { above })\end{array}$ & $\begin{array}{c}\text { Low risk } \\
(<0.85 \text { in females and }< \\
0.9 \text { in males })\end{array}$ & $\begin{array}{c}\text { High risk } \\
(\geq 0.85 \text { in females and } \geq \\
0.9 \text { in males })\end{array}$ \\
\hline Males & 31 & 52 & 17 & 39 & 61 \\
\hline Females & 39 & 34 & 27 & 37 & 63 \\
\hline Total & $\mathbf{7 0}$ & $\mathbf{8 6}$ & $\mathbf{4 4}$ & $\mathbf{7 6}$ & $\mathbf{1 2 4}$ \\
\hline
\end{tabular}

Table-2: Comparison of lipid profile in different groups based on the BMI and WHR

\begin{tabular}{|c|c|c|c|c|c|}
\hline \multirow{2}{*}{ Parameter } & \multicolumn{3}{|c|}{ BMI } & \multicolumn{2}{c|}{ Waist hip ratio } \\
\cline { 2 - 6 } & $\begin{array}{c}\text { Healthy } \\
(\mathbf{n = 7 0})\end{array}$ & $\begin{array}{c}\text { Overweight } \\
(\mathbf{n = 8 6})\end{array}$ & $\begin{array}{c}\text { Obese } \\
(\mathbf{n = 4 4})\end{array}$ & $\begin{array}{c}\text { Low risk } \\
(\mathbf{n = 7 6})\end{array}$ & $\begin{array}{c}\text { High risk } \\
(\mathbf{n = 1 2 4})\end{array}$ \\
\hline $\begin{array}{c}\text { Total } \\
\text { Cholesterol } \\
{[\mathrm{mg} / \mathrm{dL}(\mathrm{SD})]}\end{array}$ & $156.6 \pm 21.3$ & $166.1 \pm 20.1^{*}$ & $176.5 \pm 25.9^{* * *}$ & $\begin{array}{c}152.0 \pm \\
17.0\end{array}$ & $\begin{array}{c}174.2 \pm \\
22.3 * * *\end{array}$ \\
\hline $\begin{array}{c}\text { Triglyceride } \\
{[\mathrm{mg} / \mathrm{dL}(\mathrm{SD})]}\end{array}$ & $108.4 \pm 68.2$ & $136.0 \pm 52.8^{* *}$ & $186.7 \pm 61.6^{* * *}$ & $114.6 \pm$ & $153.4 \pm 65.5^{* *}$ \\
\hline $\begin{array}{c}\mathrm{HDL} \\
{[\mathrm{mg} / \mathrm{dL}(\mathrm{SD})]}\end{array}$ & $48.2 \pm 3.6$ & $48.1 \pm 2.7$ & $46.2 \pm 4.2^{* * *}$ & $48.6 \pm 2.9$ & $47.8 \pm 3.7$ \\
\hline $\begin{array}{c}\mathrm{LDL} \\
{[\mathrm{mg} / \mathrm{dL}(\mathrm{SD})]}\end{array}$ & $86.9 \pm 19.4$ & $90.72 \pm 17.8$ & $92.6 \pm 23.3$ & $80.5 \pm$ & $96.25 \pm 19.63^{*}$ \\
\hline TC/HDL & $3.3 \pm 0.5$ & $3.5 \pm 0.5^{* *}$ & $3.8 \pm 0.6^{* * *}$ & $3.1 \pm 0.4$ & $3.8 \pm 0.5^{* * *}$ \\
\hline
\end{tabular}

$*<0.05 * *<0.01 * * *<0.001$

Table-3: Table showing the Pearson Correlation Coefficient (r) and with its significance of lipid parameters with BMI and WHR.

\begin{tabular}{|c|c|c|c|c|c|c|}
\hline & & $\begin{array}{c}\text { Total } \\
\text { Cholesterol }\end{array}$ & $\begin{array}{c}\text { Serum } \\
\text { Triglyceride }\end{array}$ & HDL-C & LDL-C & TC/HDL \\
\hline \multirow{2}{*}{ BMI } & $\mathrm{r}$ & 0.308 & 0.431 & -0.202 & 0.098 & .362 \\
\cline { 2 - 7 } & P value & $<0.001$ & $<0.001$ & $<0.01$ & $\mathrm{NS}$ & $<0.001$ \\
\hline \multirow{2}{*}{ WHR } & $\mathrm{r}$ & 0.506 & 0.231 & -0.190 & 0.484 & 0.528 \\
\cline { 2 - 7 } & P value & $<0.001$ & $<0.01$ & $<0.001$ & $<0.001$ & $<0.001$ \\
\hline
\end{tabular}

As seen in Table 1, based on the waist-hip ratio, 76 participants were categorized in the low risk group wheres 124 participants belonged to the high-risk category. Study of lipid profile showed that patient in the risk group had significant higher total cholesterol, serum triglyceride, LDL and TC/HDL ratio as compared to those in the low risk group. The level of HDL was comparable in both the groups. As indicated in table 3, increases in total cholesterol, serum triglycerides, LDL-C and the TC/HDL ratio significantly correlated with increase in the WHR.

\section{Discussion}

Obesity has been identified as a global health problem. It is a common perception to relate obesity with accumulation of fat. Although true, individual with obesity also differ in their regional fat distribution. Distribution of fat around the abdominal area and upper trunk is referred to as android obesity or central obesity and is associated with greater health risk such as diabetes mellitus, athero sclerosis, coronary artery disease (CAD) etc. compared to those individuals with gynoid obesity i.e.fat distribution around the hips and thighs [10]. In India different studies has reported different prevalence for obesity and overweight. A study done in rural Kerala reported $54 \%$ of the study population to be overweight or obese [11]. In another 


\section{Original Research Article}

study in Delhi, the prevalence for obesity and over weight was $34 \%$ in males and $40 \%$ in females [12]. This variation in the prevalence can be attributed to different dietary preferences, life styles and lack of awareness all of which affects the body weight. In this study it was demonstrated that about $65 \%$ of the participants had a BMI of 25.0 and above. Of these $22 \%$ were obese and another $43 \%$ were overweight. Similar observation was made when the participant were classified basis of the Hip Waist ratio where $62 \%$ were classified as high risk (Table 1).

It has been well established that non communicable diseases such as diabetes mellitus, hypertension, CAD etc have been proved to be associated with dyslipidemia. Elevated serum triglycerides and LDL-C along with reduced levels of HDL-C are common altered lipids in these patients [13]. Anthropometric parameters are a very common and simple tool to screen high risk population for these non-communicable diseases [14]. BMI is a common and most widely used tool to classify obesity. However the BMI does not reflect on the regional distribution of fat in an individual. Individuals with similar BMI may vary in distribution around their abdominal area [15]. Moreover BMI is also reported to be affected by race and age [16].

Increased accumulation of intra-abdominal fat is associated with increased risk for development of cardio vascular disorders as excess visceral fat exposes the liver to excess fatty acid which stimulates over production of atherogenic VLDL-C and LDL-C [17]. In view of this a measure of obesity should take into consideration the intra-abdominal fat. Various tools such as waist circumference, waist to height and waist hip ratio should also be taken into consideration while classifying obesity. This study was done with an intention to observe the association and correlation between the changes in the lipid profile with anthropometric parameter especially BMI and waist hip ratio and to conclude if WHR would be an effective tool for identifying high risk population. This study revealed that serum cholesterol and serum triglycerides levels were higher in participants who were categorized in overweight and obese group in comparison to those with normal BMI. Although the increase in the cholesterol levels were statistically significant $(\mathrm{p}<0.05$ for overweight and $\mathrm{p}<0.001$ for obese group), this increase was still within the normal range. Similar pattern was observed when the participant were divided based on their WHR (Table 2). The serum triglyceride levels were however elevated both statistically ( $\mathrm{p}<$ 0.001 ) and clinically in obese group as it was above the normal recommended $150.0 \mathrm{mg} / \mathrm{dL}$. This increase in triglyceride levels can be explained by the fact that the triglycerides are stored in the adipose tissue which contributes directly to elevated BMI. In case of high risk group participants, although a slight elevation was seen in the serum triglyceride levels were seen it was statistically significant $(\mathrm{p}<0.01)$.

Similar findings were reported in a study by Shamai et al where they reported a significant rise in serum triglyceride level and no association with total cholesterol levels [18]. In the present study, although there was an inverse association with HDL-C with increasing BMI, no association was found with LDL-C. However, with respect to WHR the opposite was observed where there was a statistically significant elevated LDL in the high risk group. This variation in LDL-C could be due to the reason that it is the size and number of the LDL particle that influence its atherogenic activity rather than the concentration. Small dense LDL particle are more atherogenic that larger LDLs as small dense LDLs are removed by scavenger cells which is a critical step in the development of atherosclerosis [19]. Therefore irrespective of the concentration it is the number of LDL particle that makes the diabetic patient more prone for $\operatorname{CAD}[19,20]$.

TC/HDL-C ratio which is a predictor of CAD was significantly increasedin high risk group and obese group participants which validates thathigher fat content is associated with increased risk for CAD. In this study we also investigated the correlation between different parameters of lipid profile with BMI and WHR (Table 3 ). Correlation between total cholesterol, LDL-C and TC/HDL was stronger with increasing WHR in comparison to BMI but serum triglycerides and HDL showed stronger correlation with BMI. Various studies have reported contrasting reports regarding the dyslipidemic changes [21-25]. In a study done on 100 diabetic individuals, it was observed that WHR showed non-significant correlation with total cholesterol and LDL-C [23]. In another study done on 251 individuals only triglyceride was found to correlate with anthropometric measurements [24]. Akhelya et al in their study observed that VLDL showed positive relation and HDL-C showed inverse correlation with WHR [25]. Similarly Shamai et al found BMI to correlate positively with triglycerides and LDL-C [18]. These variation in the studies could be because obesity in particular central obesity is associated with insulin resistance due to which the metabolism of lipids are affected resulting in increased lipolysis and derangement of lipoprotein levels. As per this study 


\section{Original Research Article}

increased WHR correlated more strongly with LDL-C and $\mathrm{TC} / \mathrm{HDL}$ ratio pointing towards that fact with increase in waist circumference the risk for development for cardio vascular disease increases.

\section{Conclusion}

This study was done in order to evaluate the abnormalities in lipid profile with BMI and WHR and to establish whether WHR would be a better tool than BMI is screening the population at high risk for dyslipidemia. WHR is a direct indicator of abdominal obesity as it takes the waist circumference and hence the abdominal deposition of fat into consideration BMI on the other hand indicates the fat distribution throughout the body. This study showed that the atherogenic markers such as increased LDL-C and TC/HDL ratio correlated more strongly and significantly with WHR than with BMI. Therefore we can conclude that WHR is a good anthropometric tool to screen for high risk patients. However, in order to substantiate our finding further large scale population based study would be required.

\section{Acknowledgment}

I would like to thank all the participants for cooperating and contributing towards this study.

\section{Funding: Nil, Conflict of interest: None}

\section{Permission of IRB: Yes}

\section{Reference}

1. Unnikrishnan AG, Kalra S, Garg MK. Preventing obesity in India: Weighing the options. Indian Journal of Endo-crinology and Metabolism. 2012;16(1):4-6. doi: $10.4103 / 2230-8210.91174$.

2. Santi-Canoo MJ. Obesity and Cardiovascular Risk Factors. Obes Control Ther. 2014;1(1):1-9. http://dx. doi. org/10. 15226/2374-8354/1/1/00105

3. Rana G, Kafle D, Adhikari P, Sharma A, Sharma D.The global problem: Obesity and dyslipidemia. Int. Res J Pharm. App Sci. 2013;3(5):69-73.

4. Chehrei A, Sadrnia S, Keshteli AH, Daneshmand MA, Rezaei J. Correlation of dyslipidemia with waist to height ratio, waist circumference, and body mass index in Iranian adults.AsiaPac JClin Nutr.2007;16(2):248-53.

5. Berry DC, Stenesen D, Zeve D, Graff JM. The developmental origins of adiposetissue. Development. 2013 Oct;140 (19): 3939-49. doi: 10.1242/dev.080549.
6. Flock MR, Green MH, Kris-Etherton PM. Effects of adiposity on plasmalipidresponse to reduction sindietary saturated fatty acids and cholesterol. Adv Nutr. 2011 May; 2(3): 261-74. doi: 10.3945/an.111.000422. Epub 2011 Apr 30.

7. Klop B, Elte JW, Cabezas MC. Dyslipidemia in obesity: mechanisms and potential targets. Nutrients. 2013 Apr 12;5 (4): 1218-40. doi: 10.3390/nu5041218.

8. Lemos-Santos MG, Valente JG, Gonçalves-Silva RM, Sichieri R. Waist circumference and waist-to-hip ratio as predictors of serumconcentration of lipids in Brazilianmen. Nutrition. 2004 Oct;20(10):857-62.

9. Al-Ajlan AR. Lipid Profile in Relation to Anthropometric Measurements among College Male Students in Riyadh, Saudi Arabia: A Cross-Sectional Study. Int J Biomed Sci. 2011 Jun;7(2):112-9.

10. Ferrier DR. Lippincott's illustrated reviews. Biochemistry, $6^{\text {th }}$ ed. New Delhi: Wolters Kluwer / Lippincott William \& Wilkins Publishers Pvt Ltd;2014.

11. Binu J, Harnagle R. A Study on the prevalence of overweight and obesity and its influencing factors among rural geriatric population in Kerala. Int. J. Curr. Microbiol. App. Sci.2014;3(9):284-93.

12. Singh P, Umesh K, Dey AB. Prevalence of overweight and obesity among elderly patients attending a geriatric clinic in a tertiary care hospital in Delhi, India. Indian J Med Sci. 2004;58:162-63.

13. Mallick AK, Ahsan M. Evaluation and Interpretation of Lipid Profile Based on the National Cholesterol Education Programme Adult Treatment Panel III Guidelines. IJMHS 2016; 3(2): 123-29.

14. Manjareeka M, Nanda S, Mishra J, Mishra S. Correlation between anthropometry and lipid profile in healthy subjects of Eastern India. J Mid-life Health 2015; 6:164-8.doi 10.4103/0976-7800.172302

15. Gierach M, Gierach J, Ewertowska M, Arndt A, Junik R. Correlation between Body Mass Index and Waist Circumference in Patients with Metabolic Syndrome. ISRN Endocrinol. 2014 Mar 4;2014:514589. doi: 10.1155/2014/ 514589. eCollection 2014.

16. Zilanawala A, Davis-Kean P, Nazroo J, Sacker A, Simonton S, Kelly Y. Race/ethnic disparities in early childhood BMI, obesity and overweight in the United 
Original Research Article

Kingdom and United States. International journal of obesity. 2015;39(3):520-29.

17. Woudberg NJ, Goedecke JH, Blackhurst D, Frias M, James R, Opie LH, Lecour S. Association between ethnicity and obesity with high-density lipoprotein (HDL) function and subclass distribution. Lipids Health Dis. 2016 May 11;15:92. doi: 10.1186/s12944-0160257-9.

18. Shamai L, Lurix E, Shen M, Novaro GM, Szomstein S, Rosenthal R, Hernandez AV, Asher CR. Association of body mass index and lipidprofiles: evaluation of a broadspectrum of body mass indexpatientsincluding the morbidlyobese. Obes Surg. 2011 Jan; 21(1):42-7. doi: 10.1007/s11695-010-0170-7.

19. Huang YC, Chang PY, Hwang JS, Ning HC. Association of small dense lowdensity lipoprotein cholesterol in type 2 diabetics with coronary artery disease. Biomed J. 2014;37(6):375-79. doi: 10.4103/ 2319-4170.132883.

20. Wang J, Stančáková A, Soininen P, Kangas AJ, Paananen J, Kuusisto J, Ala-Korpela M, Laakso M. Lipoprotein subclass profiles in individuals with varying degrees of glucose tolerance: a populationbased study of 9399 Finnish men. J Intern Med. 2012 Dec; 272(6): 562-72. doi: 10.1111/j.1365-2796.2012. 02562.x. Epub 2012 Jul 27.
21. Jayarama1 N, Reddy PR, Reddy MM, Mahesh V. Relation between waist-hip ratio and lipid profile in type 2 diabetes mellitus patients Asian Journal of Medical Sciences. 2014 (5)3:51-53.

22. Aziz J, Siddiqui NA, Siddiqui IA, Omair A. Relation of body mass index with lipidprofile and blood pressure in young healthy students at Ziauddin Medical University. J Ayub Med Coll Abbottabad. 2003 OctDec; 15 (4):57-9.

23. Kanwar G, Shekhawat KS, Rathore S, Jain KB. Study of correlation of waist-hip ratio and lipid profile in type-2 diabetes mellitus subjects. J Pharm Biomed Sci 2016; 6(3): 264-68. doi. org/10.20936/jpbms/ 160236.

24. Sandhu HV, Koley S and Sandhu KS.A Study of Correlation between Lipid Profile and Body Mass Index (BMI) in Patients with Diabetes Mellitus. J. Hum. Ecol. 2008; 24(3):227-29. doi.org/10.1080/09709274.2008. 11906119.

25. Himabindu Y, Sriharibabu M, Alekhya K, Saisumanth K, Lakshmanrao N, Komali K. Correlations between anthro-pometry and lipid profile in type 2 diabetics. Indian journal of endocrinology and metabolism. 2013;17(4):727. doi.10.4103/2230-8210. 113769.

\section{How to cite this article?}

Mallick A. K, Ahsan M, Das B, Rai S. A correlation study of lipid profile with body mass index and waist hip ratio in Rohilkhand region. Int J Med Res Rev 2018;6 (03):186-191. doi:10.17511/ijmrr. 2018.i03.09. 